\title{
Research on the Application of Western Culture in Tourism Product Image Design
}

\author{
Liqin $\mathrm{Xie}^{1}$ \\ ${ }^{1}$ Applied Science College of Jiangxi University of Science and Technology, Ganzhou, Jiangxi, China
}

\begin{abstract}
Under the background of One Belt and One Road, western cultural factors, especially western taboo culture, should be taken into consideration in the image design of tourism products when developing tourism. Based on the principle of image positioning, this paper puts forward some preliminary suggestions in this regard.
\end{abstract}

\section{Introduction}

In the second half of 2013, China put forward the cooperation initiative of building the "new silk road economic belt" and the "21st century maritime silk road". Up to now, the concept of "One Belt and One Road" has gained popular support and the construction of "One Belt and One Road" has been quite effective. In the face of the new situation, the tourism industry with open and exportoriented characteristics needs to study the unique historical background of "One Belt and One Road".

China national tourism administration, said in the global tourism development report 2017, long-term global tourism as a national strategy, and national policy, Jiangxi province to seriously implement the country on the development of the global tourism industry, to develop tourism into important impetus of economic development in Jiangxi province, enter the international market, and then let all the way "area" more than 60 countries more comprehensive understanding of the rich tourism resources in Jiangxi province development advantages and prospect of tourism market development

The tourism industry and tourism culture of Jiangxi province have their own characteristics, but they are hardly known in the world. One Belt and One Road development strategy brings an opportunity for Jiangxi province tourism to go global, one of the positive ideas is to strengthen the foreign cultural factors in the image design of tourism products, so that the audience can better accept tourism products.

\section{Literature Review}

The current domestic Academia has conducted related researches on The tourism product image design. There have been 31 studies since 2000 . They study the image design of tourism products from different themes, such as tourism products, tourism image design, promotion research, tourism product development and so on.

Zhang Qian puts forward a systematic theoretical analysis and research on the brand image design of regional tourism products in the context of cultural creativity by combining design psychology, consumer psychology, aesthetic principles and other relevant theories, and comes up with the methods and strategies for the brand image design of regional tourism products. When considering tourism products, in addition to market factors, attention should be paid to the cultural characteristics of customers in a cross-cultural context. Licata Sara Fiorella Viviana design tourism products, in addition to market factors, but also attaches great importance to the cross-cultural background cultural characteristics of the customers, and the song poetry of cruise lines for the Chinese market and Italian market brochure as the research object by Hofstede's culture dimension theory to study the image of the tourism product design.

Yang Xiaoli in Shenyang Palace Museum as the carrier, in-depth development of Qing dynasty, the importance and necessity of tourism product and its basic style and cultural characteristics, and from the development of cultural tourism products in Qing dynasty and the modern culture creative product of combining the Angle, to clarify the image of the product design, positioning, and should have artistic quality, practicability and value orientation.

The above researches are relevant to the tourism product image design, the paper studies the application of foreign cultural factors in tourism product image design under the background of One Belt and One Road, in order to enhance the development of Jiangxi tourism industry.

\section{The Principle of Image Positioning of Tourism Products}

Tourism image is the overall feeling and impression left by a country or a region or a city to tourists. The setting up of tourism image in tourists' mind plays an important 
role in their choice and decision of tourism behavior. How to build an inspiring and authentic tourism image in the public mind is an important factor for the rapid development of tourism. This paper USES the principle and method of image positioning to carry out image positioning and image design of tourism products in Jiangxi province, which lays a foundation for the further development of tourism products.

The image positioning and development of tourism products must have certain background conditions. Firstly, on the basis of the systematic investigation of tourism resources in Jiangxi Province, the advantages and disadvantages of tourism resources are analyzed, the types of tourism resources are divided, and the tourism resources are quantitatively evaluated. Secondly, it analyzes the location advantages and disadvantages of Jiangxi's location and traffic conditions. At the same time, tourism service facilities, tourist behavior characteristics, tourist source conditions, regional economic conditions and policy trends in Jiangxi province are studied and analyzed. The analysis and study of these conditions is actually the feasibility study of tourism product development.

The first principle is the image positioning of tourist destinations should be based on resources. Tourism resources are the prerequisite for determining the image of a tourist destination. The tourist destination image with the advantage of resources has strong attraction and competitiveness. This positioning should highlight the most distinctive features of the region, which can represent the geographical and cultural characteristics of the region and the type of tourism resources recognized by tourists. In particular, some monopolized tourism resources have absolute competitive advantages, and tourists' sense of identity and value to their image is far greater than that of other tourism destinations.

The second principle is Market-oriented principle. The main purpose of the image positioning of a tourist destination is to obtain the recognition of potential tourists to the destination, so as to stimulate tourists' motivation and finally choose the destination to travel. Marketoriented goal is to find the docking of product features and customer market demand. The tourism resources of some tourist destinations have a certain plasticity in the characteristic positioning and product assembly. For such tourist destinations, the image of tourist destinations that meet the needs of the target market of tourists can be shaped through design and creativity. Market-oriented image positioning is based on the analysis of tourists in the target market. According to the characteristics, needs and consumption behaviors of tourists, we know how to position product features, services and marketing means.

Jiangxi province tourism opening to the world, it faces the market is the world, so its audience is the world's countries and people, these people with their own culture should be able to accept the image design of our tourism products. In other words, the image design of tourism products should be taken into account: the image design should conform to the culture of the recipient countries, so that One Belt and One Road countries can accept the products culturally and fall in love with the products psychologically. In order to achieve this goal, the most direct and fundamental is to understand the western taboo culture, so as to avoid these minefields in product image design.

\section{Western Taboo Culture}

As a cultural phenomenon, taboo culture is rooted in the reflection of cultural customs and regional and ethnic differences in people's psychology and words and deeds. Due to the differences in geographical location, cultural background, way of thinking, values and other aspects, the Chinese and the Western countries also have certain differences in language, namely, there are many differences in language taboos, which are mainly reflected in the following aspects.

The first part is plant and animal taboo. Animals and plants are necessary things in the society and have certain cultural significance. In taboo culture, animal and plant taboo is relatively important. Because due to different cultures, the same plants and animals can express different emotional colors or even completely opposite meanings. As far as animals are concerned, in China, owls are a symbol of bad luck and bad luck, and the late sleeper entering the house in Chinese means bad luck is coming. In the West, however, the owl is a symbol of wisdom. Bats are a symbol of good luck, health and happiness to the Chinese, and are sometimes used together with the Chinese character shou to express wishes to elders. For example, "five bats longevity" and so on. In the West, the mention of bats is often associated with negative thinking. The reason is that it is often a synonym for being twofaced and fickle. There is also the idiom "as blind as a bat", which means that one is as blind as a bat. In China, calling someone a dog is often considered a curse word. In the West, "happy dog" is often used to describe a lucky person. Most people love flowers. When greeting guests, flowers are presented at the airport to welcome them. The rooms are decorated with flowers and the banquet tables are arranged with flowers to adjust the atmosphere and serve as decorations. In daily life, people often take flowers as gifts to express congratulations, love, sympathy, etc. However, in China, yellow flowers symbolize inauspiciousness.

Animal vocabulary refers to the names of certain animals commonly used. Chinese people have a love-hate relationship with dogs regarding the taboo on animal vocabulary. Although dogs are now the pets of choice for most people in China, dogs have historically been used to describe bad people or bad things. For example, dog legs, $\mathrm{dog}$, dog look at people low is used to describe bad people, and with the mouth of the dog can not spit out ivory, the dog bite Lu Dongbin - do not know good hearts to insult people. However, in the West, people have had the habit of keeping dogs since ancient times, and have always had a good feeling towards dogs. So most dog idioms in western languages have relatively positive meanings. For example: Every dog has his day, be to dog, put on the dog, a lucky dog, dog-tired, etc. In China, goats, elephants, peacocks and other animals are popular with orcs. In western countries such as Britain, the goat is used to describe men who are not decent, the peacock is used to 
curse, and the elephant is a symbol of stupidity. In China, tortoise is a bad word and a relatively taboo word, and this taboo is still popular today.

The second part is color taboo. Nature is colorful, and colors have their own special meanings in the hearts of people from different countries and nations. Ancient and modern Chinese and foreign people will express different cultural mentality and different emotional colors through different color words. In western countries, there are also relatively more words for color. Although there are both similarities and differences in connotation and meaning between China and the West, due to their differences in natural environment, social system, local customs and cultural background, people may associate the same color with different emotions or symbols.

As far as western and Central countries are concerned, color preference and taboo are very different, with great differences. However, both preferences and taboos are related to the background of the occasion, that is, they are closely related to the context in which the color appears. First of all, in order to avoid communication errors caused by different color taboos in cross-cultural communication, the origin and causes of color taboos should be clarified accordingly. In China and the West, different nations will have their own inherent color worship and taboos that have been in use for a long time. As is known to all, red is the most popular color in China and the main color of the Chinese national flag. As a result, it occupies a very important position in the life of The Chinese people, who have a special attachment to red. Every wedding and other important events, almost always choose red, such as red dress, red set, red eggs, etc., China also through a variety of ways to promote the national respect for red cultural psychology.

In the process of the evolution and development of red worship, red has almost become the color pronoun representing happiness and auspiciousness, which is used to express the meaning of auspiciousness and happiness. Because of the worship of red and the cultural meaning of red, Chinese people do not want to wear red clothes in funeral affairs. It is impolite to show disrespect for the dead. Do not write in red in daily examinations. Do not write letters or names in red if possible. Sometimes red is used to mark things that cannot or are not allowed to be done. These are all manifestations of the so-called red taboo. In the West, red also represents celebration, but many western countries do not respect red as much as China. They believe that red is a sign of danger and anger. Red is somewhat frowned upon in the West because of its associations with angry faces or the color of blood, which indicates a life-threatening condition. It has an ominous connotation. Unlike the Chinese, westerners often use white wedding dresses at weddings. In English, "white" means "white", "innocent", "pure", "clean" and so on. The wedding chooses white to represent pure love, which has a positive meaning. In Western culture, "white" symbolizes light and is a symbol of God, angels, happiness, joy and virtue. In western culture, there is a tradition of heavy white taboo black, such as smart, kind, beautiful incarnation of "Snow White" is to use white to emphasize its pure goodness and beauty. The symbol of national power is the "White House" in Washington. White is chosen as a symbol to express respect and awe.

\section{Conclusion}

Only by understanding western taboo culture and avoiding these taboos in the image design of foreign tourism products can China's tourism products open the market of One Belt and One Road countries.

\section{Acknowledgment}

This research is supported by Jiangxi Education Department in 2020 College Students Innovation and Entrepreneurship Training project "Research on the Translation of Publicity Materials of Ganzhou Characteristic Tourist Attractions" (S202013434013)

\section{References}

1. Licata Sara Fiorella Viviana. Research on image Design of Cruise Tourism Products from a crosscultural Perspective [D]. East China Normal University, 2015.

2. Xiaoli Yang. Application of Manqing culture in the development of modern tourism decoration products -- image design and positioning of tourism decoration products of Shenyang imperial Palace Museum [J]. Art \& technology, 2013,26(03):174.

3. Qian Zhang. Research on brand Image Design of Regional Tourism Products based on cultural Creativity [D]. Tianjin University of Technology, 2017. 